\title{
KUALITAS PELAYANAN PUBLIK PUSKESMAS DI KABUPATEN SAROLANGUN DALAM PENCAPAIAN UNIVERSAL HEALTH COVERAGE : KAJIAN PROGRAM UPAYA KESEHATAN MASYARAKAT (UKM) BERDASARKAN DIMENSI SERVICE QUALITY
}

(Quality Of Public Health Services In Sarolangun District In Universal Health Coverage Achievements: Community Health Efforts Program Based On Service Quality Dimension)

\author{
NOVIA SUSIANTI \\ Badan Penelitian dan Pengembangan Daerah Provinsi Jambi \\ Email : susiantinovia@gmail.com
}

\begin{abstract}
To provide quality health services with easy access to the community is a challenge. The complexity of health services is still burdened with inefficiencies, errors, limited resources, and other problems, so that threaten patient accessibility and safety are still problems being faced. Customer-oriented services are an acceleration priority to improve Community Health Efforts (UKM) at District Health Centre. Orientation is done by determining a gap between performance services with expected services, one of them is dimensions service quality (Servqual) model. This study aims to determine service quality based on the Servqual model and determine priority attributes in improving service quality based on the Importance-Performance Analysis (IPA) mapping. The results showed that service quality at the Sarolangun District Health Center was superior in the dimensions of responsiveness, assurance, and empathy but still needed to improve tangible and reliability dimensions. The mapping determinant of service quality showed that the attributes to be a concern are the activities fostering the elderly, activating mutual cooperation activities by the community and the readiness officers to conducting counseling whenever community needs. Improving UKM programs through increasing community empowerment as a manifestation of community independence, maintaining and improving their health status is the main strategy that can be done.
\end{abstract}

Keywords : Servqual; Importance-Performance Analysis; Community Health Efforts; Sarolangun

\begin{abstract}
Abstrak
Memberikan pelayanan kesehatan yang bermutu dengan akses yang mudah dijangkau oleh masyarakat menjadi tantangan tersendiri. Kompleksitas pelayanan kesehatan yang masih terbebani pada inefisiensi, kesalahan, keterbatasan sumber daya dan masalah lainnya yang mengancam aksesibilitas dan keamanan pasien merupakan persoalan yang masih dihadapi. Pelayanan yang berorientasi kepada pelanggan merupakan prioritas dalam percepatan peningkatan Upaya Kesehatan Masyarakat (UKM) di puskesmas. Orientasi dilakukan dengan menentukan gap antara kinerja jasa pelayanan yang telah diberikan dengan pelayanan yang diharapkan, salah satunya melalui dimensi kualitas jasa model Service Quality (Servqual). Penelitian ini bertujuan menentukan kualitas pelayanan UKM berdasarkan model Servqual dan menentukan atribut yang menjadi proritas dalam peningkatan kualitas pelayanan berdasarkan pemetaan Importance-Performance Analysis (IPA). Hasil penelitian menunjukkan kualitas pelayanan di Puskesmas Kabupaten Sarolangun telah unggul pada dimensi responsiveness, assurance dan emphaty, namun masih perlu ditingkatkan pada dimensi tangible dan reliability. Berdasarkan pemetaan atribut penentu kualitas pelayanan ditemukan bahwa atribut yang harus menjadi perhatian utama yaitu kegiatan pembinaan lanjut usia, pengaktifan kegiatan gotong royong oleh masyarakat serta kesiapan petugas dalam melakukan penyuluhan sewaktu-waktu dibutuhkan masyarakat. Peningkatan program UKM melalui peningkatan pemberdayaan masyarakat sebagai perwujudan kemandirian masyarakat, mempertahankan dan meningkatkan status kesehatannya merupakan strategi utama yang dapat dilakukan.
\end{abstract}

Kata Kunci : Servqual; Importance-Performance Analysis; Upaya Kesehatan Masyarakat; Sarolangun

Kualitas Pelayanan Publik Puskesmas Di Kabupaten Sarolangun Dalam Pencapaian Universal Health Coverage : Kajian Program Upaya Kesehatan Masyarakat (Ukm) Berdasarkan Dimensi Service Quality - Novia Susianti | 442 


\section{PENDAHULUAN}

Pelayanan publik dilaksanakan melalui sistem kebijakan publik yang berkesinambungan, mulai dari perencanaan, implementasi hingga evaluasi. Steward, et.al (2008), kebijakan publik, "a process or a series or patterns of governmental activities or decisions that are design to remedy some public problem, either real or imagined". Pelayanan publik bukan hanya berkaitan dengan implementasi kebijakan publik, namun lebih dari itu, merupakan salah satu bentuk pemenuhan Hak Asasi Manusia (HAM) sebagai warga negara. Sebagaimana tercantum pada Universal Declaration of Human Right, yang menyatakan "everyone has the right to a standard of living adequate for the health and wellbeing of himself and of his family, including food, clothing, housing and a medical care and neseccary social services" (Christina, Indah \& Litaay, 2012).

Pelayanan kesehatan merupakan salah satu pelayanan publik dasar yang menjadi kewajiban pemerintah untuk menyelenggarakannya dengan menjamin seluruh masyarakat Indonesia mendapatkan pelayanan kesehatan terstandar. Hal tersebut merupakan wujud implikasi dari amanat UndangUndang Dasar 1945 Pasal 28H Ayat (1) dan Pasal 34 Ayat (3), bahwa kesehatan adalah hak asasi manusia dan merupakan investasi pemba-ngunan bangsa, serta negara bertanggungjawab atas penyediaan fasilitas pelayanan kesehatan dan fasilitas umum yang layak. Selain itu, Undang-Undang Nomor 36 Tahun 2009 tentang Kesehatan, Pasal 14 ayat 1 (satu) ditegaskan bahwa Pemerintah bertanggung jawab dalam merencanakan, mengatur, menyelenggarakan, membina dan mengawasi penyelenggaraan upaya kesehatan yang merata dan terjangkau oleh masyarakat (Kemenkes, 2009).

Negara-negara yang tergabung dalam World Health Organization (WHO), termasuk Indonesia pada Sidang Executive Board 144 Tahun 2019, dalam WHO $13^{\text {th }}$ General Program of Work telah mencapai kesepakatan untuk mencapai target kesehatan pada tahun 2023. Kesepakatan tersebut 
mencakup satu milyar orang mendapatkan manfaat Universal Health Coverage (UHC) atau Cakupan Kesehatan Semesta, dengan target satu milyar orang lebih terlindungi dari kedaruratan kesehatan dan satu milyar orang menikmati hidup yang lebih baik dan sehat. UHC sangat berkaitan dengan Tujuan

Pem-bangunan

Berkelanjutan

(Sustainable

Development Goals/SDGs), yang mentargetkan tahun 2030 tidak satupun orang yang tidak menikmati hasil pembangunan berkelanjutan (no one is left behind). Sehingga dalam pelaksanaannya, UHC akan sangat bertumpu pada upaya promotif, preventif termasuk pengendalian penyakit serta pelayanan kesehatan kuratif, rehabilitatif dan paliatif yang berkualitas dan efektif sesuai kebutuhan dan tidak boleh ada kendala biaya dalam memanfaatkan pelayanan tersebut (Kemenkes, 2019).

Konsep pelayanan kesehatan pada dasarnya memiliki 3 (tiga) aspek yang menjadi landasan utama sebagai fokus intervensi dan keputusan kebijakan, yaitu akses, biaya dan mutu, dikenal sebagai

triumvirate (tiga serangkai) yang saling ketergantungan, berdampak satu sama lain dan menggambarkan kinerja dimensi sistem kesehatan secara lebih luas yaitu efektif, efisien dan ekuitas (Kementerian PPN/ Bappenas; Australian Government, 2017; Kruk Freedman). Al-Assaf (2009), dibanding dua aspek lainnya, aspek mutu memiliki dampak lebih kuat terhadap pemanfaatan pelayanan kesehatan berkelanjutan dan merupakan komponen yang harus ada dan dimiliki oleh setiap pelayanan kesehatan yang tersedia. Terkait mutu, sebagai perwujudan pelayanan jasa, kualitas pelayanan kesehatan perlu diukur berdasarkan persepsi konsumen terhadap pelayanan yang diterima dengan harapan terhadap pelayanan yang akan diterima (Al-Assaf,2009; Handayani, Ma'ruf \&Sopacua, 2010; Kruk \& Freedman, 2008).

\begin{tabular}{lr}
\multicolumn{2}{c}{ Pengukuran jualitas } \\
pelayanan menurut \\
Parasuraman, et.al (1994) dalam \\
Tjiptono (2005), dapat diukur melalui \\
lima dimensi kualitas jasa, terdiri \\
dari reliabilitas (reliability), daya \\
tanggap (responsiveness), jaminan
\end{tabular}
Masyarakat (Ukm) Berdasarkan Dimensi Service Quality - Novia Susianti | 444 
(assurance), empati (emphaty) dan bukti fisik (tangible). Demikian pula halnya dengan pelayanan kesehatan, sebagai salah satu perwujudan sektor jasa yang merupakan proses atau aktivitas tidak berwujud (intangible) yang biasanya terjadi pada interaksi antara pelanggan dan pemberi jasa atau sumber daya fisik lainnya, maka pelayanan kesehatan dapat diukur melalui Model Service Quality. Model ini membandingkan kinerja jasa pada atribut-atribut relevan dengan standar ideal/sempurna untuk masing-masing atribut jasa. Bila kinerja sesuai atau melebihi standar, maka persepsi atas kualitas jasa keseluruhan akan positif dan sebaliknya. Model ini me-nganalisis gap antara dua variabel pokok, yakni jasa yang diharapkan (expected service) dan jasa yang dipersepsikan (perceived service).

Memberikan pelayanan kesehatan yang bermutu dengan akses yang mudah dijangkau oleh masyarakat menjadi tantangan tersendiri. Terlebih pelayanan kesehatan merupakan bidang yang sangat kompleks, penuh kontroversi dan kontradiksi dengan berbagai kemajuan teknologi dan pengobatan modern. Akan tetapi saat ini pelayanan kesehatan masih terbebani dengan inefisiensi, kesalahan, keterbatasan sumber daya dan masalah lainnya yang mengancam aksesibilitas dan keamanan pasien (Tolga Taner, Sezen \& Antony, 2007). Pusat Kesehatan Masyarakat (Puskesmas) merupakan upaya perwujudan hal tersebut. Puskesmas menyediakan pelayanan kesehatan oleh pemerintah hingga ke pedesaan dengan program pokok wajib upaya kesehatan, salah satunya Upaya Kesehatan Masyarakat (UKM) (Bappenas, 2018; Sudian,2012) .

UKM adalah upaya kesehatan yang memelihara dan meningkatkan kesehatan serta mencegah dan menanggulangi timbulnya masalah kesehatan dengan sasaran keluarga, kelompok dan masyarakat, dilaksa-nakan melalui upaya esensial dan pengembangan. Upaya esensial diselenggarakan oleh setiap puskes-mas untuk mendukung pencapaian Standar Pelayanan Minimal (SPM) kabupaten/kota pada bidang 
kesehatan. Sedangkan upaya pengembangan meliputi kegiatan yang memerlukan inovatif dan atau ekstensifikasi dan intensifikasi pelayanan disesuaikan dengan prioritas masalah kesehatan, kekhususan wilayah kerja dan potensi sumber daya yang tersedia (Bappenas, 2018; Kemenkes 2014).

Tak dapat dipungkiri bahwa pelayanan kesehatan di puskesmas masih memerlukan daya ungkit yang tak sedikit dalam mencapai UHC. Beberapa hasil penelitian menunjukkan bahwa masih ditemukan gap antara kualitas pelayanan kesehatan yang diterima dengan kualitas pelayanan yang diharapkan oleh masyarakat, dengan terdapat pengaruh antara dimensi pembentuk kualitas pelayanan (reliability, responsiveness, assurance, emphaty dan tangible) dengan tingkat kepuasan pelayanan yang diterima (Miranty, Darmawansyah \& Amir, 2013; Panggato, Lampus \& Kaunang, 2013; Sudian, 2012).

Mengingat kompleksitas kegiatan pelayanan di puskesmas meliputi pelayanan perorangan dan masyarakat, diperkirakan akan ditemukan kendala-kendala dalam pelaksanaannya. Hal ini dapat menimbulkan persepsi kurang baik dari masyarakat terhadap kinerja puskesmas, apabila pelayanan yang diterima kurang atau tidak sesuai dengan harapannya. Oleh karena itu, memberikan pelayanan sesuai dengan harapan masyarakat tentunya merupakan salah solusi yang dapat diupayakan. Berdasarkan hal tersebut, penting untuk mengetahui kualitas pelayanan yang telah diberikan dan pelayanan yang diharapkan masyarakat berdasarkan model Service Quality (Servqual) dengan menganalisis gap antara pelayanan yang diharapkan dengan pelayanan yang diterima oleh masyarakat.

Berdasarkan uraian latar belakang di atas, adapun tujuan penelitian ini adalah :

1. Menentukan kualitas pelayanan Upaya Kesehatan Masyarakat (UKM) berdasarkan atribut penentu kualitas pelayanan model Service Quality (Servqual) di puskesmas seKabupaten Sarolangun.

2. Menentukan atribut prioritas penentu kualitas pelayanan model Service Quality 
(Servqual)

pemetaan

berdasarkan

Importance-

Performance Analysis (IPA) di

puskesmas

se-Kabupaten

Sarolangun.

\section{TINJAUAN PUSTAKA}

\section{Puskesmas}

Pusat Kesehatan Masyarakat
yang selanjutnya disebut Puskesmas
adalah salah satu jenis fasilitas
pelayanan kesehatan $r$ tingkat
pertama yang memiliki peranan
penting dalam sistem kesehatan
nasional, khususnya subsistem
upaya kesehatan r yang
menyelenggarakan upaya kesehatan
masyarakat dan upaya kesehatan perseorangan tingkat pertama.

Puskesmas merupakan suatu tempat yang digunakan untuk menyelenggarakan upaya pelayanan kesehatan baik promotif, preventif, kuratif maupun rehabilitatif yang dilakukan oleh pemerintah, pemerintah daerah dan/atau masyarakat dengan lebih mengutamakan upaya promotif dan preventif, untuk mencapai derajat kesehatan masyarakat yang setinggi-tingginya di wilayah kerjanya (Al-Assaf, 2009; Kemenkes, 2014;
Kementerian PPN/Bappenas; Austra-lian Government, 2017).

Puskesmas dalam penyelenggaraannya melaksanakan Upaya Kesehatan Masyarakat (UKM) dan Upaya Kesehatan Perseorangan (UKP). UKM adalah setiap kegiatan untuk memelihara dan meningkatkan kesehatan serta mencegah dan menanggulangi timbulnya masalah kesehatan dengan sasaran keluarga, kelompok dan masyarakat. Se-dangkan UKP adalah suatu kegiatan dan/atau serangkaian kegiatan pelayanan kesehatan yang ditujukan untuk peningkatan, pencegahan, penyembuhan penyakit, pengurangan penderitaan akibat penyakit dan memulihkan kesehatan perseorangan (Kemenkes, 2014).

Pembangunan kesehatan yang diselenggarakan puskesmas bertu-juan untuk mewujudkan masyarakat yang (Kemenkes, 2014)

a. Memiliki perilaku sehat yang meliputi kemampuan hidup sehat;

b. Mampu menjangkau pelayanan kesehatan bermutu; 
c. Hidup dalam lingkungan sehat; dan

d. Memiliki derajat kesehatan yang optimal, baik individu, keluarga, kelompok dan masyarakat.

\section{Pengukuran Kualitas Jasa Model Servqual}

Parasuraman, et.al (1994), model Servqual didasarkan pada asumsi bahwa konsumen membandingkan kinerja jasa pada atribut-atribut yang relevan dengan standar ideal/sempurna untuk masing-masing atribut jasa. Bila kinerja sesuai atau melebihi standar, maka persepsi atas kualitas jasa keseluruhan akan positif dan sebalinya. Dengan kata lain, model ini menganalisis gap antara dua variabel pokok, yakni jasa yang diharapkan (expected service) dan jasa yang dipersepsikan (perceived service) (F. Tjiptono \& Chandra, 2007).
Pengukuran kualitas jasa dalam Servqual didasarkan pada skala multi-item yang dirancang untuk mengukur harapan dan persepsi pelanggan, serta gab diantara keduanya pada lima dimensi utama kualitas jasa (reliability, respon-siveness, assurance, emphaty, tangible). Kelima dimensi utama tersebut dijabarkan oleh aribut rinci variabel harapan dan persepsi yang disusun berdasarkan pernyataan skala Likert.

Evaluasi kualitas jasa model Servqual mencakup perhitungan perbedaan antara nilai yang diberikan para pelanggan untuk setiap pasang pernyataan berkaitan dengan harapan dan persepsi. Skor masing-masing dihitung berdasarkan rumus menurut Zeithalm, et.al, 1990 dalam Tjiptono (2005), yaitu :

Skor SERVQUAL = Skor Persepsi - Skor Harapan

Adapun dimensi dan atribut model Servqual, dapat dilihat pada tabel berikut

\section{Table 1. Dimensi dan Atribut Model Servqual}

\begin{tabular}{|c|l|cl|}
\hline No & \multicolumn{1}{|c|}{ Dimensi } & & \multicolumn{1}{c|}{ Atribut } \\
\hline 1 & Reliabilitas & $>$ & Menyediakan jasa sesuai yang dinginkan \\
& & $>$ & Dapat diandalkan dalam menangani masalah jasa pelanggan \\
& & $>$ & Kesigapan menyampaikan jasa sesuai dengan waktu yang \\
& & $>$ & dijanjikan \\
& & $>$ & Menyampaikan jasa secara benar sejak pertama kali \\
& & Menyimpan dokumen tanpa kesalahan \\
\hline
\end{tabular}




\begin{tabular}{|c|c|c|}
\hline 2 & Daya Tanggap & $\begin{array}{l}>\text { Menginformasikan pelanggan tentang kepastian waktu } \\
\text { penyampaian jasa } \\
\text { Layanan yang segera/cepat bagi pelanggan } \\
\text { Kesediaan membantu pelanggan } \\
\text { Kesiapan merespons, memberi informasi kepada pelanggan }\end{array}$ \\
\hline 3 & Jaminan & $\begin{array}{l}\text { Karyawan yang menumbuhkan rasa percaya pada pelanggan } \\
\text { Kesungguhan sehingga membuat pelanggan merasa aman } \\
\text { sewaktu melakukan transaksi } \\
\text { Karyawan yang konsisten bersikap sopan } \\
\text { Karyawan yang mampu menjawab pertanyaan pelanggan }\end{array}$ \\
\hline 4 & Empati & $\begin{array}{l}\text { Memberikan perhatian individual kepada para pelanggan } \\
\text { Karyawan memperlakukan pelanggan secara penuh perhatian } \\
\text { Kesungguhan mengutamakan kepentingan pelanggan } \\
\text { Karyawan memahami kebutuhan pelanggan } \\
\text { Waktu beroperasi (jam kantor) yang nyaman }\end{array}$ \\
\hline 5 & Bukti Fisik & $\begin{array}{l}>\text { Peralatan modern } \\
>\quad \text { Kasilitas yang berdaya tarik visual } \\
>\quad \text { Karyawan yang berpenampilan rapi dan profesional }\end{array}$ \\
\hline
\end{tabular}

Sumber: Diadaptasi dari Parasuraman et.al (1994) (Fandy Tjiptono, 2012)

\section{METODE PENELITIAN}

Penelitian ini menggunakan pendekatan kuantitatif desain crosssectional. Populasi penelitian adalah masyarakat di wilayah kerja puskesmas. Sampel adalah pasien yang datang berkunjung ke puskesmas baik rawat jalan maupun rawat inap, dengan jumlah 517 orang. Teknik pengambilan sampel berda-sarkan nonprobabilitas sampling, berdasarkan kriteria : (1) Sampel unit rawat jalan, yaitu pasien yang datang berkunjung dan yang terdata di unit rawat jalan puskesmas dengan kunjungan telah lebih dari 1 kali; dan (2) Sampel unit rawat inap, yaitu pasien yang pada saat pendataan sedang mendapatkan perawatan minimal 1×24 jam.
Penelitian dilakukan pada bulan Maret-Juli 2018. Analisis data menggunakan Spss Versi 23. Pengumpulan data primer melalui wawancara kepada responden menggunakan kuesioner, dilakukan di puskesmas untuk responden yang berkunjung serta dilakukan di rumah untuk responden yang tidak berkunjung ke puskesmas ketika penelitian sedang dilakukan. Untuk masing-masing pertanyaan atribut kualitas jasa pelayanan diukur melalui skala Likert, dan diberi nilai untuk masing-masing pilihan jawaban, sebagai berikut :

(1) Tidak Baik/Tidak Penting; bernilai 1 untuk pernyataan positif dan 4 untuk pernyataan negatif 
(2) Kurang Baik/Kurang Penting; bernilai 2 untuk pernyataan positif dan 4 untuk pernyataan negatif

(3) Baik/ Penting; bernilai 3 untuk pernyataan positif dan 3 untuk pernyataan negative

(4) Sangat Baik/Sangat Penting; bernilai 4 untuk pernyataan positif dan 4 untuk pernyataan negatif.

Selanjutnya untuk setiap dimensi dikategorikan menjadi :

(1) Baik, jika $\geq$ mean untuk data berdistribusi normal, dan median untuk data tidak berdistribusi normal.

(2) Kurang baik, jika < mean untuk data berdistribusi normal dan median untuk data tidak berdistribusi normal.

Analisis data adalah analisis univariat untuk menjelaskan persentase responden berdasarkan atribut kualitas jasa pelayanan dan analisis Importance-Performance untuk membandingkan nilai rata-rata atribut pelayanan kesehatan berdasarkan kenyataan dan harapan.

\section{HASIL PENELITIAN}

\section{Kualitas Pelayanan pada Upaya Kesehatan Masyarakat (UKM) Dimensi Servqual}

Pengukuran kualitas pelayanan upaya kesehatan masyarakat di wilayah kerja puskesmas seKabupaten Sarolangun diukur berdasarkan indikator Servqual, melalui dimensi tangible (bukti fisik), reliability(keandalan), responsiveness (daya tanggap), assurance (jaminan) dan emphaty (kepedulian). Berdasarkan hasil analisis, distribusi frekuensi responden yang menyatakan kualitas dimensi pelayanan tangible (bukti fisik) termasuk kategori baik, yaitu sebanyak 394 orang (76,21\%) dan 123 orang yang menyatakan kurang baik (23,79\%). Untuk dimensi reliability (keandalan), sebanyak 352 orang (68,09\%) responden menyatakan baik dan masih terdapat 165 orang $(31,91 \%)$ yang menyatakan kurang baik.

Dimensi responsiveness (daya tanggap) terdapat 499 orang responden (96,52\%) yang menyatakan sudah baik dan terdapat 18 orang $(3,48 \%)$ yang menyatakan kurang baik. Untuk dimensi assurance (jaminan) terdapat 511 orang $(98,84 \%)$ yang menyatakan sudah baik dan hanya 6 orang $(3,48 \%)$ yang menyatakan 
kurang baik. Hampir sama dengan dimensi assurance (jaminan), dimensi emphaty juga telah mendapatkan $98,10 \%$ penilaian baik dari 507 orang responden dan hanya 10 orang $(1,9 \%)$ yang menyatakan kurang baik. Untuk lebih jelas dapat dilihat pada tabel berikut :

Tabel 2. Performance Dimensi Kualitas Pelayanan UKM di Puskesmas SeKabupaten Sarolangun

\begin{tabular}{|c|l|r|r|r|r|r|}
\hline \multirow{2}{*}{ No } & \multirow{2}{*}{$\begin{array}{c}\text { Pernyataan Variabel } \\
\text { Unsur Kualitas } \\
\text { Pelayanan }\end{array}$} & \multicolumn{3}{|c|}{ Kategori Performance Kualitas Pelayanan UKM } \\
\cline { 3 - 7 } & & \multicolumn{2}{|c|}{$\begin{array}{c}\text { Kurang Baik } \\
\text { N }\end{array}$} & $\mathbf{N}$ & \multicolumn{1}{c|}{ Baik } & Jumlah \\
\hline 1 & Tangible (Bukti Langsung) & 123 & 23,79 & 394 & 76,21 & 517 \\
\hline 2 & Reliability (Keandalan) & 165 & 31,91 & 352 & 68,09 & 517 \\
\hline 3 & $\begin{array}{l}\text { Responsiveness (Daya } \\
\text { Tanggap) }\end{array}$ & 18 & 3,48 & 499 & 96,52 & 517 \\
\hline 4 & Assurance (Jaminan) & 6 & 1,16 & 511 & 98,84 & 517 \\
\hline 5 & Empathy (Kepedulian) & 10 & 1,90 & 507 & 98,10 & 517 \\
\hline
\end{tabular}

Sumber : Data Primer Diolah

Distribusi frekuensi dimensi

kualitas pelayanan pada Upaya Sarolangun dibentuk oleh atribut Kesehatan Masyarakat (UKM) di pembentuknya. Performance atributpuskesmas dalam Kabupaten atribut tersebut dapat dilihat pada tabel

Table 3. Performance Atribut Pembentuk Dimensi Kualitas Pelayanan UKM di Puskesmas se-Kabupaten Sarolangun Tahun 2018

\begin{tabular}{|c|c|c|c|c|c|c|}
\hline \multirow{3}{*}{ No } & \multirow{3}{*}{$\begin{array}{l}\text { Pernyataan Variabel Unsur } \\
\text { Kualitas Pelayanan }\end{array}$} & \multicolumn{5}{|c|}{$\begin{array}{c}\text { Kategori Performance Kualitas Pelayanan } \\
\text { UKM }\end{array}$} \\
\hline & & \multicolumn{2}{|c|}{ Kurang Baik } & \multicolumn{2}{|c|}{ Baik } & \multirow[t]{2}{*}{ Jumlah } \\
\hline & & $\mathbf{n}$ & $\%$ & $\mathbf{n}$ & $\%$ & \\
\hline$A$ & Tangible (Bukti Langsung) & & & & & \\
\hline 1 & $\begin{array}{ll}\text { Keberadaan } & \text { posyandu } \\
\text { mudah dijangkau } & \end{array}$ & 58 & 11,22 & 459 & 88,78 & 517 \\
\hline 2 & $\begin{array}{ll}\text { Terdapat } & \text { kegiatan } \\
\text { pembinaan lansia } & \end{array}$ & 127 & 24,56 & 390 & 67,36 & 517 \\
\hline 3 & $\begin{array}{l}\text { Kegiatan penyuluhan kepada } \\
\text { masyarakat }\end{array}$ & 27 & 5,22 & 490 & 84,63 & 517 \\
\hline 4 & Kegiatan gotong royong rutin & 511 & 98,84 & 6 & 1,04 & 517 \\
\hline 5 & Kegiatan senam bersama & 507 & 98,07 & 10 & 1,73 & 517 \\
\hline$B$ & Reliability (Keandalan) & & & & & \\
\hline 6 & $\begin{array}{l}\text { Petugas dapat diandalkan } \\
\text { dalam mengajak masyarakat } \\
\text { hidup sehat }\end{array}$ & 64 & 12,38 & 453 & 87,62 & 517 \\
\hline 7 & $\begin{array}{ll}\text { Petugas dapat } & \text { diandalkan } \\
\text { dalam } & \text { melakukan } \\
\text { penyuluhan } & \end{array}$ & 65 & 12,57 & 452 & 87,43 & 517 \\
\hline
\end{tabular}

451 | Khazanah Intelektual Volume 3 Nomor 2 Tahun 2019 


\begin{tabular}{|c|c|c|c|c|c|c|}
\hline 8 & $\begin{array}{l}\text { Petugas selalu rutin ikut serta } \\
\text { pada kegiatan di masyrakat }\end{array}$ & 163 & 31,53 & 354 & 68,47 & 517 \\
\hline C & $\begin{array}{l}\text { Responsiveness (Daya } \\
\text { Tanggap) }\end{array}$ & & & & & \\
\hline 9 & $\begin{array}{l}\text { Petugas cepat tanggap } \\
\text { dalam merespons penyakit } \\
\text { yang dapat menular di } \\
\text { masyarakat }\end{array}$ & 56 & 10,83 & 461 & 89,16 & 517 \\
\hline 10 & $\begin{array}{l}\text { Petugas cepat tanggap } \\
\text { dalam kegiatan yang ada di } \\
\text { masyarakat }\end{array}$ & 17 & 13,64 & 500 & 86,36 & 517 \\
\hline 11 & $\begin{array}{l}\text { Penyuluhan dalam } \\
\text { memberikan informasi cepat } \\
\text { dilakukan oleh petugas }\end{array}$ & 62 & 11,90 & 455 & 78,58 & 517 \\
\hline 12 & $\begin{array}{l}\text { Petugas tanggap dalam } \\
\text { melakukan gerakan PSN }\end{array}$ & 56 & 10,80 & 461 & 79,62 & 517 \\
\hline $\mathrm{D}$ & Assurance (Jaminan) & & & & & \\
\hline 13 & $\begin{array}{l}\text { Petugas menumbuhkan rasa } \\
\text { percaya kepada masyarakat }\end{array}$ & 57 & 11,03 & 460 & 79,45 & 517 \\
\hline 14 & $\begin{array}{l}\text { Petugas terampil dalam } \\
\text { melakukan penyuluhan }\end{array}$ & 60 & 11,61 & 457 & 88,39 & 517 \\
\hline 15 & $\begin{array}{lr}\text { Petugas } & \text { konsisten dalam } \\
\text { melakukan } & \text { Petugas } \\
\text { konsisten } & \text { melakukan } \\
\text { kegiatan } & \text { berbasis } \\
\text { masyarakat } & \end{array}$ & 56 & 10,83 & 461 & 89,17 & 517 \\
\hline 16 & $\begin{array}{l}\text { Petugas } \quad \text { terampil dalam } \\
\text { mengajak } \\
\text { sehas }\end{array}$ & 58 & 11,22 & 459 & 88,78 & 517 \\
\hline$E$ & Emphaty (Kepedulian) & & & & & \\
\hline 17 & $\begin{array}{l}\text { Petugas peduli terhadap } \\
\text { kesehatan warga sekitar }\end{array}$ & 55 & 10,64 & 462 & 89,36 & 517 \\
\hline 18 & $\begin{array}{lr}\text { Petugas } & \text { sunggu-sungguh } \\
\text { mengajak } & \text { masyarakat } \\
\text { berperan dalam } & \text { kegiatan } \\
\text { posyandu dll } & \end{array}$ & 56 & 10,83 & 461 & 89,17 & 517 \\
\hline 19 & $\begin{array}{lr}\text { Petugas } & \text { sungguh } \\
\text { mengutamakan } & \text { kepentingan } \\
\text { masyarakat } & \end{array}$ & 10 & 1,93 & 452 & 87,43 & 462 \\
\hline 20 & $\begin{array}{l}\text { Jadwal kegiatan dapat diikuti } \\
\text { oleh masyarakat }\end{array}$ & 55 & 10,64 & 462 & 89,36 & 517 \\
\hline
\end{tabular}

Sumber : Data Primer Diolah

Pada tabel di atas, distribusi frekuensi atribut pembentuk dimensi tangible (bukti fisik), kegiatan gotong royong rutin merupakan atribut yang paling banyak dinilai kurang baik oleh 511 orang responden (98,84\%). Demikian pula kegiatan senam bersama yang dilaksanakan masyarakat dengan 507 orang $(98,07 \%)$ menyatakan kurang baik. 
Jangkauan keberadaan posyandu sebanyak 507 orang responden $(88,6 \%)$ menyatakan sudah mudah dijangkau. Sementara itu, atribut kegiatan penyuluhan kepada masyarakat hanya 490 orang $(67,36 \%)$ yang menyatakan baik dan demikian halnya pembinaan lansia dengan persentase yang sama.

Kegiatan Upaya Kesehatan Masyarakat (UKM) yang dilaksanakan oleh, untuk dan dari masyarakat sendiri belum terlaksana dengan baik. Memang tak dapat dipungkiri, memberikan rasa memiliki kepada masyarakat untuk melakukan kegiatan-kegiatan rutin yang berdampak pada kesehatan bukan sesuatu yang mudah, seperti kegiatan gotong royong rutin dan senam bersama yang dilakukan dan diinisiasi oleh masyarakat itu sendiri dalam hal ini masyarakat di Kabupaten Sarolangun. Perlunya upaya lebih banyak lagi dalam memberikan sosialisasi ataupun penyuluhan kepada masyarakat agar masyarakat memiliki kesadaran dan kemauan untuk hidup sehat dimulai dari perilaku hidup sehat.

Atribut pembentuk dimensi reliability (keandalan), persentase tertinggi menurut responden adalah petugas sudah dapat diandalkan dalam mengajak masyarakat hidup sehat dengan jumlah 453 responden $(87,62 \%)$, diikuti petugas dapat diandalkan dalam melakukan penyuluhan dengan jumlah 452 orang responden $(87,43 \%)$ dan petugas rutin ikut serta pada kegiatan di masyarakat dengan jumlah 354 orang $(68,47 \%)$. Hasil ini sejalan dengan hasil temuan pada dimensi tangible dimana kegiatan yang diinisiasi oleh petugas telah mendapatkan penilaian baik oleh responden. Namun kegiatan yang diinisiasi oleh masyarakat belum dikategorikan baik. Adanya asumsi petugas masih terbatas pada kegiatan puskesmas menjadi penyebab hal ini.

Berbeda pada dimensi responsiveness (daya tanggap), hampir semua atribut telah dinilai baik oleh responden dengan persentase $>80 \%$. Atribut dengan persentase tertinggi untuk kategori baik pada ketanggapan petugas dalam melakukan gerakan PSN dengan persentase $89,29 \%$, diikuti petugas cepat tanggap dalam merespon penyakit yang dapat menular di masyarakat sebanyak $89,16 \%$, penyuluhan dalam memberikan 
informasi yang cepat kepada masyarakat sebesar $88,43 \%$ dan petugas cepat tanggap dalam kegiatan yang ada di masyarakat sebesar 86,36\%. Ketanggapan petugas pada atribut-atribut dimensi responsiveness (daya tanggap) sejalan dengan tangible (bukti fisik) dan reliability (keandalan), dimana kegiatan yang bersifat program dari puskesmas (tidak diinisiasi oleh masyarakat) telah dinilai baik pelaksanaannya. Terlebih untuk kegiatan PSN, dimana hal tersebut telah menjadi target kinerja dari puskesmas.

Atribut-atribut pembentuk dimensi assurance (jaminan) mendapatkan persentase tertinggi untuk penilaian baik yaitu konsistensi petugas dalam melakukan kegiatan berbasis masyarakat sebesar $89,17 \%$, diikuti petugas terampil dalam mengajak masyarakat untuk hidup sehat dengan persentase $88,78 \%$, petugas terampil dalam melakukan penyuluhan sebesar $88,39 \%$ dan petugas menumbuhkan rasa percaya kepada masyarakat sebesar 79,45\%. Hal tersebut menjadi kekuatan bagi pihak puskesmas untuk menumbuhkan rasa percaya kepada masyarakat. Petugas kesehatan juga dituntut untuk menjadi role model (contoh peran) bagi masyarakat dalam melakukan gerakan hidup sehat, dan kepercayaan menjadi modal utama dalam hal ini.

Sementara itu, pada dimensi emphaty (kepedulian), sebanyak $89,36 \%$ responden menyatakan petugas telah peduli terhadap kesehatan warga sekitar, 89,17\% petugas telah sungguh-sungguh mengajak masyarakat berperan dalam kegiatan posyandu, sebesar $87,43 \%$ petugas mengutamakan kepentingan masyarakat dan sebesar $89,35 \%$ responden menyatakan bahwa jadwal kegiatan puskesmas dapat diikuti oleh masyarakat. Kepedulian merupakan hal yang menunjukkan bahwa petugas kesehatan telah memiliki rasa tanggung jawab melebihi tugas dan fungsinya sebagai petugas kesehatan dalam upaya peningkatan kesehatan masyarakat. Hal ini merupakan kekuatan dasar yang harus dimiliki oleh pihak petugas kesehatan dalam upaya peningkatan kesehatan masyarakat.

Beberapa hasil penelitian menunjukkan emphaty (kepedulian) yang dimiliki oleh petugas kesehatan 
akan meningkatkan rasa puas dari masyarakat dan hal ini merupakan peluang dalam terus meningkatkan mutu pelayanan (Busra, 2008; Naomi, 2008; Sudian 2012).

Pemetaan Dimensi Service Quality (Servqual) Upaya Kesehatan Masyarakat pada Pelayanan Kesehatan di Puskesmas se-Kabupaten Sarolangun berdasarkan Importance-Performance Analysis
Pengukuran kualitas pelayanan pada Upaya Kesehatan Masyarakat (UKM) di puskesmas se-Kabupaten Sarolangun yang dianalisis berdasarkan ImportancePerformance Analysis (IPA) yang diukur melalui atribut (dimensi) kualitas jasa Servqual, yaitu tangibles, reliability, respon-siveness, assurance dan emphaty, dilakukan dengan membandingkan nilai rata-rata seperti pada tabel berikut :

Table 4. Nilai Rata-rata Per Dimensi Pelayanan Service Quality (Servqual) Upaya Kesehatan Masyarakat Pada Pelayanan Kesehatan di Puskesmas se-Kabupaten Sarolangun

\begin{tabular}{|r|l|r|r|r|}
\hline No & Pernyataan Variabel Unsur Kualitas Jasa & $\begin{array}{c}\text { Mean } \\
\text { Performance }\end{array}$ & $\begin{array}{c}\text { Mean } \\
\text { Importance }\end{array}$ & GAP \\
\hline A & Dimensi Tangibles (Bukti Langsung) & & & \\
\hline 1 & Keberadaan Posyandu Mudah Dijangkau & 3 & 3,02 & 0,02 \\
\hline 2 & Terdapat Kegiatan Pembinaan Lansia & 2,75 & 3,04 & 0,29 \\
\hline 3 & $\begin{array}{l}\text { Kegiatan Penyuluhan kepada } \\
\text { Masyarakat }\end{array}$ & 2,95 & 3,03 & 0,08 \\
\hline 4 & $\begin{array}{l}\text { Kegiatan Gotong Royong Diinisiasi } \\
\text { Masyarakat }\end{array}$ & 2,02 & 3,03 & 1,01 \\
\hline 5 & $\begin{array}{l}\text { Kegiatan Senam Bersama Diinisiasi } \\
\text { Masyarakat }\end{array}$ & 2,02 & 3 & 0,98 \\
\hline B & $\begin{array}{l}\text { Dimensi Reliability (Keandalan) } \\
\text { Petugas dapat Diandalkan dalam } \\
\text { Mengajak Masyarakat Hidup Sehat }\end{array}$ & 3 & 3,11 & 0,11 \\
\hline 2 & $\begin{array}{l}\text { Petugas dapat Diandalkan dalam } \\
\text { Melakukan Penyuluhan }\end{array}$ & 2,99 & 3,02 & 0,03 \\
\hline 3 & $\begin{array}{l}\text { Petugas Selalu Rutin Ikut Serta pada } \\
\text { Kegiatan di Masyarakat }\end{array}$ & 2,68 & 3 & 0,32 \\
\hline C & Responsiveness (Daya Tanggap) & & & \\
\hline 1 & $\begin{array}{l}\text { Petugas Cepat Tanggap dalam } \\
\text { Merespons Pencegahan Penyakit } \\
\text { Menular di Masyarakat }\end{array}$ & 3 & 3,21 & 0,21 \\
\hline 2 & $\begin{array}{l}\text { Petugas Cepat Tanggap dalam Kegiatan } \\
\text { yang ada di Masyarakat }\end{array}$ & 2,96 & 3,02 & 0,06 \\
\hline 3 & $\begin{array}{l}\text { Petugas Cepat dalam Memberikan } \\
\text { Informasi kepada Masyarakat }\end{array}$ & 2,99 & 3,04 & 0,05 \\
\hline 4 & $\begin{array}{l}\text { Petugas Tanggap dalam Melakukan } \\
\text { Gerakan PSN }\end{array}$ & 3,01 & 3,2 & 0,19 \\
\hline
\end{tabular}

455 | Khazanah Intelektual Volume 3 Nomor 2 Tahun 2019 


\begin{tabular}{|c|c|c|c|c|}
\hline D & Assurance (Jaminan) & & & \\
\hline 1 & $\begin{array}{l}\text { Petugas Menumbuhkan Rasa Percaya } \\
\text { kepada Masyarakat }\end{array}$ & 2,99 & 3 & 0,01 \\
\hline 2 & $\begin{array}{l}\text { Petugas Terampil dalam Melakukan } \\
\text { Penyuluhan }\end{array}$ & 2,99 & 3 & 0,01 \\
\hline 3 & $\begin{array}{l}\text { Petugas Konsisten dalam Melakukan } \\
\text { Kegiatan Berbasis Masyarakat }\end{array}$ & 3 & 3 & 0 \\
\hline 4 & $\begin{array}{l}\text { Petugas Terampil dalam Mengajak } \\
\text { Masyarakat Hidup Sehat }\end{array}$ & 2,99 & 3 & 0,01 \\
\hline$E$ & Emphaty (Kepedulian) & & & \\
\hline 1 & $\begin{array}{l}\text { Petugas Peduli terhadap Kesehatan } \\
\text { Warga Sekitar }\end{array}$ & 3 & 3,01 & 0,01 \\
\hline 2 & $\begin{array}{l}\text { Petugas Sungguh-sungguh Mengajak } \\
\text { Masyarakat Berperan dalam Kegiatan } \\
\text { Posyandu dll }\end{array}$ & 3 & 3,1 & 0,1 \\
\hline 3 & $\begin{array}{l}\text { Petugas Mengutamakan Kepentingan } \\
\text { Masyarakat untuk Hidup Sehat }\end{array}$ & 2,98 & 3 & 0,02 \\
\hline 4 & $\begin{array}{l}\text { Jadwal Kegiatan di Masyarakat dapat } \\
\text { Diikuti oleh Masyarakat }\end{array}$ & 3 & 3 & 0 \\
\hline
\end{tabular}

Sumber : Data Primer Diolah

Berdasarkan tabel di atas, penyuluhan kepada masyarakat diketahui bahwa deviasi atribut- dengan nilai Gap 0,08 dan keberadaan atribut dimensi Upaya Kesehatan Masyarakat (UKM) pada masyarakat di wilayah kerja puskesmas seKabupaten Sarolangun berdasarkan indikator Servqual, ditemukan deviasi tertinggi pada dimensi tangibles (bukti fisik), yaitu pada kegiatan gotong royong yang diinisiasi oleh masyarakat dengan nilai gap antara mean importance dan mean perfor-mance 1,01 , diikuti kegiatan senam bersama yang diinisiasi masyarakat dengan nilai gap 0,98 .

Nilai Gap selanjutnya pada kegiatan pembinaan lansia dengan nilai 0,29 , diikuti kegiatan posyandu yang mudah dijangkau dengan nilai Gap 0,02.

Nilai gap tertinggi pada dimensi reliability (keandalan) adalah petugas selalu rutin ikut serta pada kegiatan di masyarakat dengan nilai Gap 0,32, diikuti petugas dapat diandalkan dalam mengajak masyarakat untuk hidup sehat dengan nilai Gap 0,11 dan petugas dapat diandalkan dalam melakukan penyuluhan dengan nilai Gap 0,03.

Dimensi responsiveness (daya tanggap), nilai gap tertinggi ditemu-kan pada ketanggapan petugas untuk merespon terjadinya penularan 
penyakit di masyarakat, dengan nilai Gap 0,21. Walaupun nilai performance telah cukup tinggi yaitu 3,00 akan tetapi importance (harapan) masyarakat cukup tinggi dengan nilai mean 3,21.

\section{Importance}

(harapan) masyara-kat terhadap ketanggapan petugas dalam melakukan pemberantasan dan penularan Demam Berdarah Dengue (DBD) untuk melakukan gerakan Pemberantasan Sarang Nyamuk (PSN) juga cukup tinggi dengan nilai mean 3,2 sehingga nilai Gap dengan performance juga cukup tinggi yaitu 0,19 . Atribut kecepatan petugas dalam memberikan informasi kepada masyarakat nilai Gap performance dan importance 0,06 serta kecepatan pemberian infor-masi kepada masyarakat dengan nilai Gap 0,05 .

Dimensi assurance (jaminan), nilai gap sangat kecil berkisar pada nilai 0 pada semua atribut pembentuknya, demikian pula pada dimensi emphaty (kepedulian). Nilai mean performance (kinerja) berkisar antara titik 3 menunjukkan kualitas pelayanan (kinerja) telah mampu ditunjukkan oleh petugas dan nilai importance (harapan) yang tidak terlalu jauh perbedaannya dengan performance menunjukkan masyarakat telah cukup puas terhadap pelayanan pada kedua dimensi ini. Pemetaan dimensi pelayanan berdasarkan importanceperformance analysis atribut dimensi pelayanan, maka diperoleh peta untuk masingmasing pertanyaan, yaitu seperti pada gambar diagram berikut :

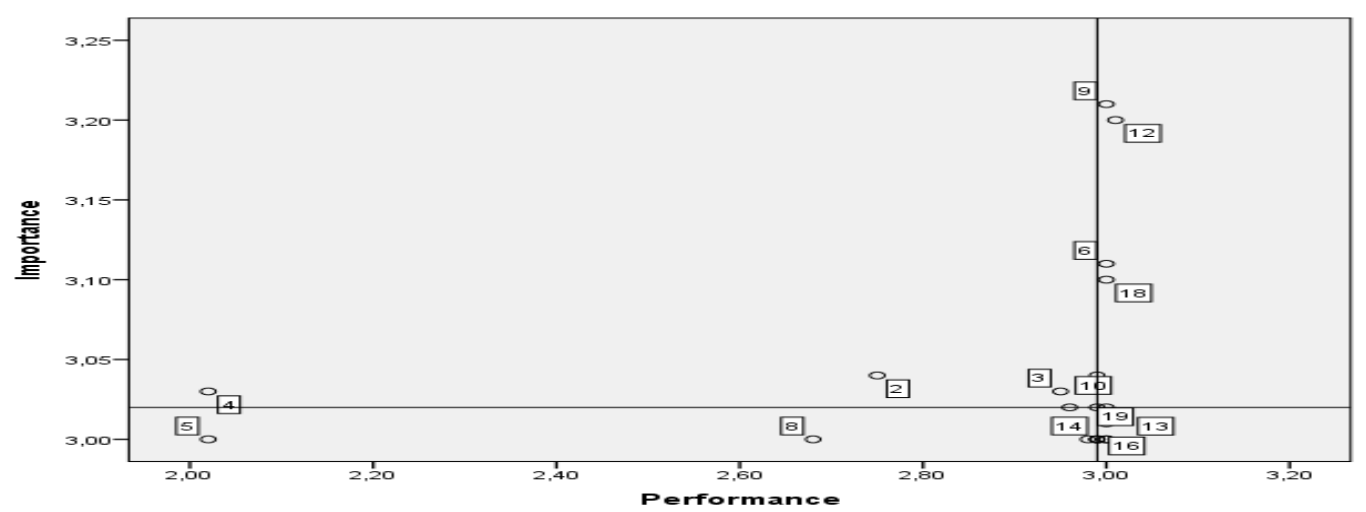

Gambar 1 Matrix Importance-Performance Analysis (Diagram Kartesius) Dimensi Service Quality pada Upaya Kesehatan Masyarakat di Wilayah Kerja Puskesmas dalam Kabupaten Sarolangun 
Berdasarkan gambar di atas, penyuluhan yang sewaktu-waktu terdapat sebaran yang hampir merata dari seluruh atribut-atribut dibutuhkan oleh masyarakat.

Kuadran II yang menunjukkan atau unsur penentu dimensi keunggulan dan harus dipertahankan kepuasan pasien pada ke-4 kuadran diagram kartesius berdasarkan indikator Service Quality di puskesmas dalam Kabupaten Sarolangun. Kuadran I yang berada pada bagian kiri atas yang menunjukkan bahwa nilai kepentingan akan atribut pelayanan sangat tinggi sedangkan performa/pelayanan yang didapatkan responden masih sangat rendah juga masih cukup banyak. Kuadran ini sebaiknya menjadi perhatian utama bagi pihak puskesmas dalam upaya peningkatan kualitas pelayanan. Titik teratas yaitu kegiatan pembinaan lanjut usia. Masyarakat memiliki nilai harapan yang cukup tinggi namun petugas dianggap belum mampu mewujudkannya. Penyuluhan kepada masyarakat adalah atribut selanjutnya yang perlu segera menjadi prioritas untuk dilaksanakan. Demikian pula gotong royong rutin, ketanggapan petugas terhadap kegiatan di masyarakat, serta terdiri dari ketanggapan petugas dalam merespon penyakit yang dapat menular di masyarakat, ketanggapan petugas dalam gerakan PSN, petugas dapat diandalkan dalam mengajak masyarakat hidup sehat, kesungguhan petugas dalam kegiatan posyandu dan keandalan petugas dalam melakukan penyuluhan.

Kuadran III yang menunjukkan perbaikan namun dengan prioritas yang rendah terdiri dari kegiatan senam bersama, petugas diharapkan rutin ikut serta dalam kegiatan di masyarakat, petugas menumbuhkan rasa percaya kepada masyarakat, keterampilan petugas dalam penyuluhan, demikian pula dengan keterampilan petugas mengajak masyarakat hidup sehat dan petugas mengutamakan kepentingan masyarakat. Kuadran ini menunjukkan bahwa petugas belum mampu memberikan kinerja yang baik akan tetapi harapan masyarakat terhadap hal tersebut juga rendah. Mengingat kinerja belum mampu ditunjukkan oleh pihak 
puskesmas, dirasa tetap perlu pelaksanaan program dan belum ada menjadi perhatian walaupun prioritasnya rendah.

Kuadran IV menunjukkan kegiatan yang diinisiasi dari masyarakat.

Upaya peningkatan kesadaran kinerja puskesmas telah melebihi bahwa masalah kesehatan bukan rata-rata harapan masyarakat. hanya permasalahan di bidang Atribut tersebut yaitu akses kesehatan harus diupayakan lebih keberadaan posyandu, petugas gencar lagi. Diperlukan program yang konsisten melakukan kegiatan berbasis masyarakat, kepedulian petugas terhadap kesehatan warga sekitar, kesungguhan petugas mengutama-kan kepentingan masyarakat, dan jadwal kegiatan telah dapat diikuti oleh masyarakat. Program Upaya Kesehatan Masyarakat telah dilaksanakan oleh puskesmas, terlihat pada kuadrankuadran tersebut, akan tetapi masih dapat merangsang masyarakat lebih peduli terhadap kesehatan pribadi, keluarga maupun lingkungannya.

Ringkasan atribut pelayanan untuk setiap kuadran-kuadran pemetaan gap antara performa pelayanan dan kepentingan/harapan masyarakat terhadap UKM di wilayah kerja puskesmas se-Kabupaten Sarolangun, yaitu :

Table 7. Atribut Kepuasan Masyarakat Terhadap Pelaksanaan Upaya Kesehatan Masyarakat (UKM) Berdasarkan Importance-Performance Analysis (IPA) Diagram I, II, III dan IV di Puskesmas dalam Kabupaten Sarolangun

\begin{tabular}{|c|c|}
\hline Kuadran I. Prioritas Perbaikan & $\begin{array}{l}\text { Kuadran II. Keunggulan dan Harus } \\
\text { Dipertahankan }\end{array}$ \\
\hline $\begin{array}{l}\text { 1. Kegiatan pembinaan lansia } \\
\text { 2. Penyuluhan ke masyarakat } \\
\text { 3. Gotong royong rutin } \\
\text { 10. Ketanggapan petugas terhadap kegiatan } \\
\text { di masyarakat } \\
\text { 11. Penyuluhan cepat dilakukan oleh petugas } \\
\text { sewaktu-waktu }\end{array}$ & $\begin{array}{l}\text { 3. Ketanggapan petugas dalam merespons } \\
\text { penyakit yang dapat menulari penyakit } \\
\text { 12. Ketanggapan petugas dalam gerakan } \\
\text { PSN } \\
\text { 6. Petugas dapat diandalkan dlm mengajak } \\
\text { masyarakat hidup sehat } \\
\text { 18. Kesungguhan petugas mengajak } \\
\text { berperan dalam posyandu dll } \\
\text { 7. Keandalan petugas dalam } \\
\text { melakukan penyuluhan }\end{array}$ \\
\hline
\end{tabular}




\begin{tabular}{|c|c|}
\hline $\begin{array}{l}\text { Kuadran III. Perbaikan dengan Prioritas } \\
\text { Rendah }\end{array}$ & Kuadran IV. Berlebihan \\
\hline 4. Kegiatan senam bersama & 1. Akses keberadaan posyandu \\
\hline $\begin{array}{l}\text { 8. Petugas rutin ikut serta di kegiatan } \\
\text { masyarakat }\end{array}$ & $\begin{array}{l}\text { 15. Petugas konsisten melakukan kegiatan } \\
\text { berbasis masyarakat }\end{array}$ \\
\hline $\begin{array}{l}\text { 13. Petugas menumbuhkan rasa percaya } \\
\text { kepada masyarakat }\end{array}$ & $\begin{array}{l}\text { 16. Kepedulian petugas terhadap kesehatan } \\
\text { warga sekitar }\end{array}$ \\
\hline $\begin{array}{l}\text { 14. Keterampilan petugas dalam penyuluhan } \\
\text { 16. Keterampilan petugas mengajak } \\
\text { masyarakat hidup sehat }\end{array}$ & $\begin{array}{l}\text { 19. Kesungguhan petugas } \\
\text { mengutamakan } \\
\text { masyarakat }\end{array}$ \\
\hline $\begin{array}{l}\text { 19. Petugas mengutamakan } \\
\text { kepentingan masyarakat }\end{array}$ & $\begin{array}{l}\text { 20. Jadwal kegiatan } \\
\text { masyarakat }\end{array}$ \\
\hline
\end{tabular}

Sumber : Data Primer Diolah

KESIMPULAN

Kualitas pelayanan pada Upaya Kesehatan Masyarakat (UKM) di puskesmas dalam Kabupaten Sarolangun telah unggul pada dimensi responsiveness, assurance dan emphaty, namun masih harus meningkatkan kualitas pada dimensi tangible dan reliability. Atribut yang harus menjadi perhatian utama berdasarkan pemetaan pembentuk dimensi-dimensi tersebut yaitu kegiatan pembinaan lanjut usia, pengaktifan kegiatan gotong royong oleh masyarakat serta kesiapan petugas dalam melakukan penyuluhan sewaktu-waktu dibutuhkan masyarakat.

Peningkatan program UKM melalui upaya pemberdayaan masyarakat dalam mewujudkan kemandirian hidup sehat, memper- tahankan dan meningkatkan status kesehatannya merupakan strategi utama yang dapat dilakukan, melalui kegiatan spesifik ke masyarakat berdasarkan kelompok-kelompok usia dengan mengaktifkan peran serta masyarakat.

\section{SARAN}

Pihak puskesmas diharapkan dapat lebih mengedepankan upaya pemberdayaan masyarakat dalam melakukan Upaya Kesehatan Masyarakat. Pihak Dinas Kesehatan diharapkan dapat mensinergikan upaya peningkatan status akreditasi puskesmas dengan peningkatan Upaya Kesehatan Masyarakat (UKM).

\section{DAFTAR PUSTAKA}

Al-Assaf, A. (2009). Mutu Pelayanan Kesehatan (Ketiga). Jakarta: EGC.

Bappenas. (2018). Penguatan Pelayanan Kesehatan Dasar di Puskemas. 
Busra. (2008). Kualitas Pelayanan Dan Kepuasan Pasien Jaminan Kesehatan Aceh.

Christina, O. :, Indah, M., \& Litaay, T. (2012). Implementasi pelayanan publik yang berintegritas dalam pemerintahan (Studi kasus di kota Kupang, provinsi NTT). 70 halaman.

Handayani, L., Ma'ruf, N. A., \& Kemenkes. (2009). Undang-Undang Kesehatan Nomor 36 Tahun 2009. https://doi.org/http://www. depkes.go.id/resources/downloa d/general/UU\%20Nomor\%2036 \%20Tahun2\%20009\%20tentang $\% 20 K e s e h a t a n . p d f$

Kementerian Kesehatan. (2014). Permenkes No. 75 Tahun 2014 tentang Pusat Kesehatan Masyarakat. https://doi.org/DOI: 10.1016/j.cell.2009.01.043

Kementerian Kesehatan. (2019). Kemenkes Targetkan Universal Health Coverage. 1-5.

Kementrian

PPN/Bappenas; Australian Government. (2017). Meningkatkan Pelayanan Dasar Lini Depan, Menggagas Penguatan Peran Kecamatan dan Unit Layanan di Kecamatan. (April).

Kruk, M. E., \& Freedman, L. P. (2008). Assessing health system performance in developing countries: A review of the literature. Health Policy, 85(3), 263-276. https://doi.org/10.1016 /J.HEALTHPOL.2007.09.003.

Miranty, K., Darmawansyah, \& Amir, M. Y. (2013). Faktor yang Berhubungan dengan Kepuasan Pasien Rawat Jalan di Puskesmas Rantepao Kabupaten Toraja Utara Tahun
Sopacua, E. (2010). Peran Tenaga Kesehatan sebagai Pelaksana Pelayanan Kese-hatan Puskesmas. Buletin Penelitian Sistem Kesehatan, 13(1), 12-20. Retrieved from http://ejournal.litbang.depkes.go.id /index.php/hsr/article/view/2752/15 10

2013. (12), 1-12.

Naomi, P. (2008). Pengukuran Tingkat Kepuasan Pelanggan Terhadap Jasa Pelayanan Kesehatan (Menggunakan Metode Performance Importance Analysis di Unit Rawat Inap Rumah Sakit Umum Sumedang).

Panggato, S., Lampus, B. S., \& Kaunang, W. (2013). Tingkat Kepuasan Pasien Rawat Jalan Terhadap Ketepatan Waktu Pelayanan Oleh Tenaga Kesehatan di Puskesmas Ranotana Weru Kecamatan Wanea Kota Manado. Jurnal EBiomedik, 1(1), 2011-2014. https://doi.org/10.35790/ebm.1.1.2 013.1168

461 | Khazanah Intelektual Volume 3 Nomor 2 Tahun 2019 